\title{
An Analysis on Adult Learners' Satisfaction in Online Education Programmes
}

\author{
$\underline{\text { https://doi.org/10.3991/ijim.v12i7.9665 }}$ \\ Huey Zher $\mathrm{Ng}\left({ }^{凶}\right)$ \\ INCEIF, Malaysia \\ nhzher@gmail.com \\ Sakina Sofia Baharom \\ MARA Corporation, Malaysia
}

\begin{abstract}
The demand for online programmes is continuously increasing at varying degrees, with the major appeal coming from adult learners whom are managing with the numerous demands from other work and life domains. These adult learners have their own varied expectations from the online learning process. The purpose of this paper is to investigate the degree to which other predictors contribute to adult learners' satisfaction in online learning environment. A mixed-methods design was used, selecting both quantitative methods (utilizing survey research) and qualitative methods (employing open-ended questionnaire items), gathering the feedback of 200 adult learners whom comprises of secondary school teachers and college level teachers, enrolled in professional online courses. The online courses were designed using a problem-centered and case-based approach to learning and utilized technologies including learning management system (LMS) such as Moodle as well as functions from the LMS. The results showed that the items such as learner-content interaction, selfregulated learning design, and Internet self-efficacy were good predictors of students' satisfaction. Implications of these findings for higher education in providing blended or online programmes for adult learners are also discussed.
\end{abstract}

Keywords-Online learning environment, adult-learners, learning design, professional learning

\section{Introduction}

Online learning has been growing rapidly. The rapid evolution of online learning is due to the flexible conditions offered to the learners: everywhere or anywhere and anytime at the learner's convenience. Nagel (2009) predicted that by 2014, majority of the students would sign-up for college classes online. While the metamorphosis of the Internet has expedited the rapid increase of online learning, online courses provide the very much needed flexibility to adult students whom are balancing extra responsibilities.

Adult students do face many of the challenges a student would commonly face but adult students have other commitments, such as fulltime job and families (Choy, 
2002; Forbus, Newbold, \& Mehta, 2011; Haley \& Booker, 2012; Park \& Choi, 2009). Thus, the growing population of adult students may be more susceptible to enrolling in the rising number of online courses because online learning may fit more easily into a busy schedule (Bourdeaux \& Schoenack, 2016). Adult learners have distinct needs and requirements. Hence, online instructors are advised to carefully consider adult learners' different learning characteristics to help them learn best (Huang, 2002). Osgood-Treston (2001) review on adult (online) learner studies proposes that adult learners search for suitable learning environments which permit them to adapt to the role of student while managing with the numerous demands from other work and life domains. Furthermore, adult learners who feel unsupported in an online course may quit their enrollment in the course (Park \& Choi, 2009).

Research has indicated that learners' satisfaction is a crucial marker of the quality of learning experiences (Moore \& Kearsley, 1996; Yukselturk \& Yildirim, 2008). For example, Parsad \& Lewis (2008) argued that the quality of interaction in an online setting largely depended on the technology tools applied during learning. On the other hand, there are other researchers like Artino (2007) and Puzziferro (2008) whom mentioned that online learners who were unable to regulate learning efficiently were unlikely to be satisfied. Since digital technologies have change the way learners interact with both instructors and peers (Kaminski, Switzer, \& Gloeckner, 2009), it is gainful to explore learners' satisfaction in online learning settings. Therefore, this study seeks to investigate the degree to which predictors contribute to adult learners' satisfaction in online learning environment.

\section{$1 \quad$ Literature Review}

\subsection{Adult learning}

The term adult learner comes in various definitions as illustrated by the following studies.

Some definitions revolve around age such as the study by Forbus et al. (2011) which defined as an adult student when he or she is above 24 years of age, employed and working full-time, and often times supporting dependents (such as spouse, parents) at home.

On the other hand, there are other definitions which focus in traditional schooling or adoption of life course roles. Darkenwald \& Merriam (1982) mentioned, "adult education is a process whereby persons whose major social roles are characteristic of adult status undertake systematic and sustained learning activities for the purpose of bringing about changes in knowledge, attitudes, values and skills." A study by Choy (2002) defined adult students with the following characteristics: financial independence, part-time pursuit of classes, delayed enrollment, and possibly even lacking a diploma from high school. Myers et.al (2011) argued that it is the social roles which the individual is supporting that defines someone as an adult learner. 
Most adults enrolled into educational programs willingly and multi-task their classes around work and family responsibilities (Cercone, 2008). Additionally, adult learners are also highly motivated and task-oriented (Merriam \& Caffarella, 1999).

Andragogy, the theory of adult education advocated by Malcolm Knowles in the late 20th century, implement six assumptions on the adult learner to best understand and acclimatize their educational needs. According to Merriam et al. (2007), these six assumptions are:

- Adult learners are self-directed learners and act independently.

- Adult learners have gained valuable experiences in their lives and value applying their experiences to the learning process.

- Adult learners are eager and ready to learn what they need to leam to succeed.

- Adult learners are interested in the application of learning in-order to problemsolve.

- Adult learners are more internally motivated and less so by outside forces.

- Adult learners are interested in understanding the value of what they are being taught.

These six assumptions create challenges to the creation and management of an online learning environment for adult learners. The following section overviews online learning environment.

\subsection{Online Learning Environment}

Allen and Seaman (2015) defined online course as one in which at least $80 \%$ of the course content is delivered online. The steady increase on enrolment for online learning (Merriam et. al, 2007) is driven by the student's demand for flexible modes of delivery, and the potential for cost savings, such as travelling and time which are extinguished by the virtual environment (Michael, 2012). This iteration of online learning has also capitalized on an expanding population having access to the Internet (Tainsh, 2016).

As mentioned in the earlier section, adult students are swamped with commitments such as balancing a job, family responsibilities, and an education. Hence, online learning is more convenient than attending a physical class (Bishop, 2002). At the same time, the flexibility of time presented by online courses supports adult students in balancing both work and family commitment while still pursuing a degree (Alexander, Perreault, Zhao, \& Waldman, 2009; Choy, 2002). Despite its growing popularity on the higher education landscape; however, facilitators and instructors of online courses have yet to provide effective online delivery of instruction (Sugar, Martindale, \& Crawley, 2007).

Cranton (1996) concluded that how an individual adult learns is different and shaped by his/her personal history and contexts. A study by Tweedell (2000) also illustrated that adult learners are using online learning environment with different sets of expectations that are based on their personal histories. 
Therefore, online educators need to understand their adult students to design more meaningful online learning experiences or activities for them. Based on the recent qualitative study done by Bourdeaux \& Schoenack (2016), student expectations of online instructors are divided into the following aspects: clarity, respect, and intentional design and students were less satisfied if their expectations for clarity, respect, or intentional design were not meet. Prior to that, suggestions for the use of andragogy while teaching with technology often include statements about its flexibility and capacity to make adult learners move through lessons anytime, anywhere, and at their own pace (Njiro, 2014). In other words, instructors and facilitators need to be aware of what adults want and need (Cercone, 2008). Cercone's proposed two approaches based on adult learners' characteristics: (1) design the online learning environment based on adult learners' limitations. (2) consider adult learners' individual learning experiences in online instruction.

\section{Research Purpose}

As acknowledging learners' online learning experience is significant for future online pedagogical design, this study aimed to investigate the degree to which predictors contribute to adult learners' satisfaction in online learning environment.

The research question of this study is as followed:

How much importance does each predictor contribute to adult learner's satisfaction in an online learning environment?

\subsection{Context}

Before moving on to the methodology and analysed data, there is a need to understand the approach-design and management applied on the online course offered by the organisation. The online professional course used in this study is on Flipping Classroom to Active Learning. It was provided to the organisation's secondary school teachers and college lecturers. The online professional course was one of the courses offered under the category Educator Competencies. This is the first of its kind initiative conducted by the organisation. The initiative began the implementation in 2017. The professional courses are fully online. This was a one-month professional course. Within the one-month duration, the learners were to work on their own time to complete the tasks given. This course was run on Moodle (Refer to Fig. 1), a Learning Management System (LMS) platform. 


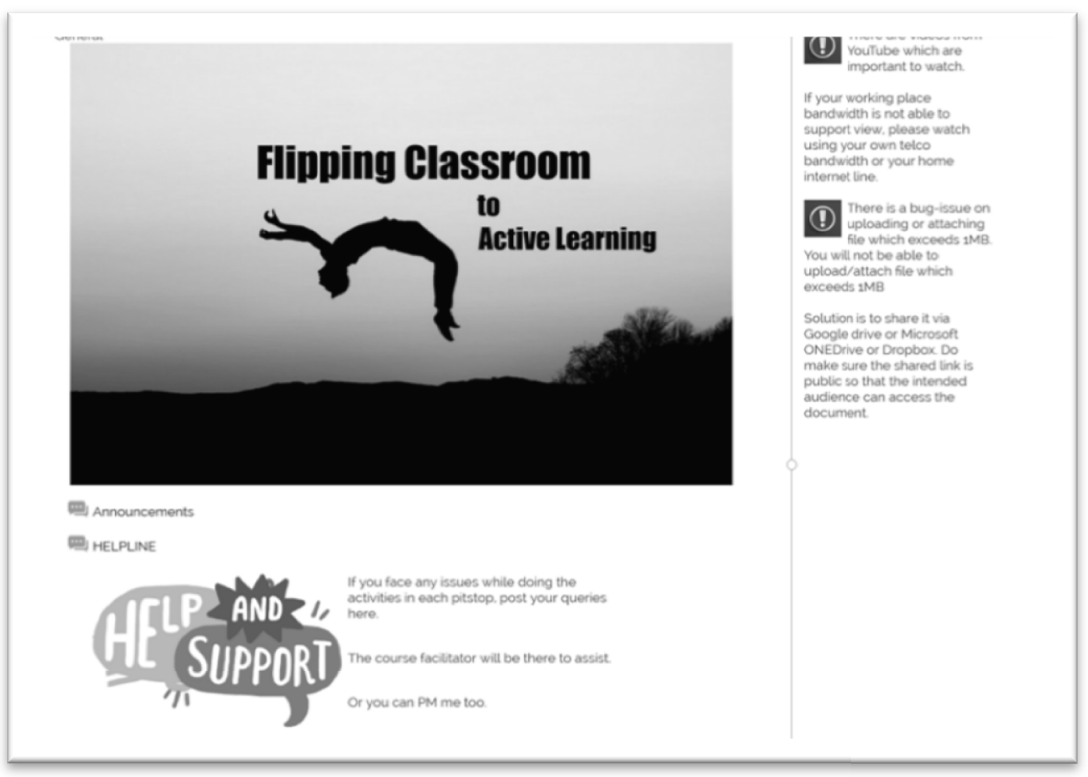

Fig. 1. Front page of the online course on the Moodle platform

From this online programme, the participants would experience the flipped classroom. They will explore how it can impact student learning and how one can implement it to transform their teaching subject. By modelling a flipped approach, the participant would receive access to information and resources to begin their exploration of flipped classroom possibilities prior to attending the course. This interactive course focused on engaging with other participants so that participants can work collaboratively to develop a plan for flipping at least one lesson in a course.

- Explore concrete strategies for "flipping" courses.

- Identify pedagogical strategies for teaching in a flipped classroom.

- Explore techniques for exposing students to content before class.

- Develop an individual plan for "flipping" a class in an upcoming course.

In this online course, the topics or sessions are known as PITSTOP. There are multiple pit-stops or stages which the learners had to enter. Each pit-stop consisted of information, and activities, which the learners had to complete, either as an individual or a team. Completed activities per pit-stop would allow the learner to fulfil the requirement(s) of the following pit-stop. The accumulated skills gathered in each pitstop were to assist the learners to piece the puzzles together in designing and developing Flipped lesson. The following is the list of PITSTOPS (Refer to Fig 2) for this online programme:-

- Pit Stop \#1 Getting to Know

- Pit Stop \#2 Planning

- Pit Stop \#3 Tools to Use 
After PITSTOP \#3, there is an extra section called as READY TO GO. This was a section which the learner had to submit their work based on the collected skills from all the PITSTOPs. Those who had completed the online professional course would receive a e-badge of completion. In this online course, the digital badge functions as an alternative credentialing system which summarizes the learner's achievement and accomplishment (Gibson et al, 2015).

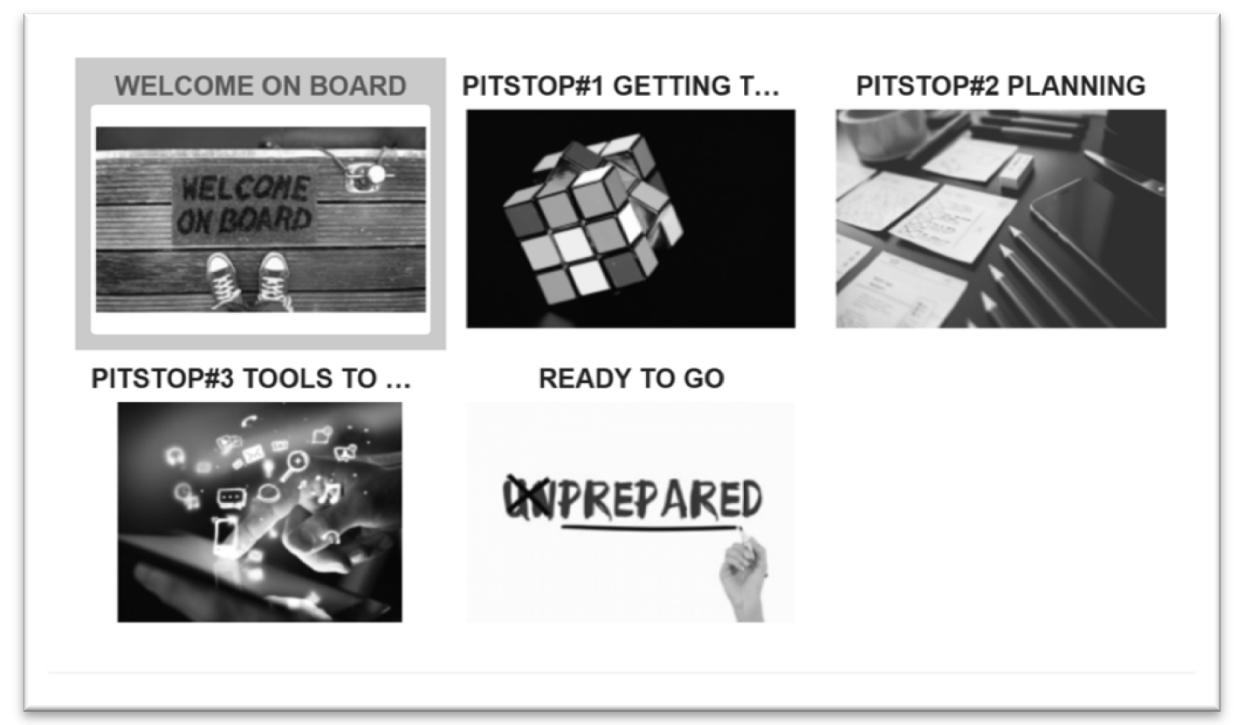

Fig. 2. The arrangement and flow of the Pit Stop for the course

\subsection{Participants}

The sample of this study of secondary school teachers and college lecturers enrolled in this online course. Three hundred sixty and one (361) learners signed up for this online course. All the participants' signed-up did not occur before the start of the online course. There were learners who signed up in the middle of the duration while there were some whom signed up a week before the course ended. The participants did not have any experience in participating in a fully online professional course. Each participant was given a guideline (in a digital form) on how to access and use the platform functions such as replying forum. At the end of the course, only one hundred and eight-six (186) completed the online course.

\subsection{Methodology}

Instrumentation. In pursuance of analysing the predictors contributing to the adult learners' satisfaction in an online course, a survey method was administered. A survey questionnaire comprises of fourteen (14) Likert scale questions and two (2) 
open-ended questions. Data from these 14 statements served as the quantitative data for this study.

- I found access to the course material flexible and convenient.

- The online course was easy to navigate.

- Course objectives were clearly presented.

- The online training met my expectations

- The course was well-organized.

- Adequate time was provided for questions and discussions

- Course materials were available in a format that suited me.

- Learning activities encouraged me to use the available learning materials and resources.

- Learning activities encouraged me to research for additional material

- The range of online course resources (eg, pdf articles, web links etc) helped me to carry out the online activities.

- The workload for the online activities was manageable

- The online activities made studying the course interesting and engaging

- The course has encouraged me to manage my own learning.

- What I learned in the course built on my prior knowledge in the field.

The open-ended questions were: (a) The best features of the course were This course could be improved by _. The purpose of the open-ended questions was not only to provide voice to the chosen scale, but also to identify other variables which was not covered in the quantitative section. Data from this open-ended question served as the qualitative data for this study. The survey questionnaire was placed on the LMS platform and attempted by the participants after they have completed the online course. The data from the questionnaire was also collected through the course LMS. Simple statistics were used to describe both quantitative and qualitative data. From the 186 participants, 174 did the survey.

Research Approach for Qualitative data collection. To interpret the qualitative data, the research methodology phenomenography was applied. This is a research approach developed to answer questions on how the participants see their experience. The outcomes of phenomenographic analysis are different content-related categories describing the differences in people's ways of experiencing and conceiving their world (Yang \& Tsai, 2017). The participants were asked to answer to open-ended questions on the studied phenomenon. Their responses are then arranged according to conceptual categories. It is noted that the collected responses are the participants' expressions of their experiences, and that the analysis and outcomes are the researchers' interpretations of the participants' expressions of their experiences.

The content-related categories were adopted from the predictors developed by Gómez-Rey, Barbera \& Fernández-Navarro (2016). According to Gómez-Rey et. al, the predictors comprise a complete educational process which focuses on the learners' expectation on deeper and engaged learning. Furthermore, the predictors which represents the students' perceptions focus on specific parts of the course or evaluate the quality of the learning experience. The adopted predictors are (1) Learning content, (2) Knowledge acquisition, (3) Instruction, (4) Learning platform, (5) Course 
design, (6) Ability to transfer, (7) Instructor presence and social support. In this study, the reply from each participant would be categorized in each adopted predictor. The frequency of mentioned would be accounted for the weight of each predictor.

\section{$3 \quad$ Analysed Data}

\subsection{Learning Content}

Providing learners with engaging and meaningful course materials such as journal articles, newspaper articles, online simulations, games, interactive tutorials, maps, graphs, and images, would support students' readiness to learn, and orientation for learning, while encouraging intrinsic motivation (Arnold \& Conaway, 2016).

These following statements represented the quantitative section of the survey.

Course materials were available in a format that suited me. - $89 \%$

The range of online course resources (eg, pdf articles, web links etc) helped me to carry out the online activities. $-91 \%$

The percentage is the accumulative of the Likert scale 4 (agree) and 5 (strongly agree). As seen above, the participants' choice on the both scales echoed their positive satisfaction on the online learning experience according to the item-course design. This was represented in their written feedback from the open-ended questions.

94 participants have specifically mentioned that the selection of various materials such as videos from the YouTube platform and various web resources have deepened their understanding on the course as illustrated in the following extracted reply.

"...explanation of ideas are in form of video which is dynamic and interesting."

Adding to this, the materials shared via the online course also come with the purpose to assist them in their professional work. Arnold \& Conaway (2016) argued that learners may feel a stronger motivation toward course materials that are related to solving problems in the workplace. This is clearly seen in the following reply. The first reply indicated that the resources had encouraged the participant to change his/her teaching approach to flipped method.

"This course list all possible resources and links that can be useful for teachers and students. The lesson video was very interesting and easy to be understand. The best features of this course is about 54 Flipped Classroom Tools For Teachers and Students. This course had encouraged me to change teaching style from conventional method to flipped method to make a better and interesting lesson."

The next reply indicated that a suitable source was essential in providing the participants clarity in applying the information in their teaching and learning.

"I especially like all the videos featured in this course as they allow me to have a better picture in handling flipped classroom in a real-life situation."

There are many thousands and more resources on flip learning method. The participants would have come across on some of them. Hence, it is crucial for the instructor to filter the most suitable and correct information on flip learning. The following feedback exhibited that the participant was able to obtain the right method to conduct flip learning in his/her classroom. 
"I learned the appropriate arrangement of FLIPPING CLASSROOM."

Subsequently this would increase their satisfaction towards the online course.

Knowledge Acquisition. Xie \& Ke (2011) argued that the creation of new knowledge is achieved when learners are persistent towards online learning activities. The challenge for online instructors is to identify who are the participants and provide useful course content, which would motivate collaborative and interactive learning (Brindley et al., 2009). Therefore, the course content and presentation of the online delivery should be designed to encourage learners participating in meaningful knowledge acquisition activities. 45 participants mentioned that they acquired the knowledge intended for the learners. This number does not include another 10 participants whom mentioned phrases such as "Good" or "Excellent" which indicated positive overall performance of the online course.

"This course greatly facilitates the addition of science in handling problems in classroom teaching and how to handle learners. besides that, this knowledge can help teachers to be more creative in conveying knowledge."

"Learnt lots. Challenging. Very hands-on. Open-ended tasks, self-directed learning "done right".

Ability to transfer. This variable is described as the expectation that learners will apply the knowledge gained in the course to future situations. Mayer (2002) included the ability to transfer as the second of the two most important educational goals. This element brings knowledge acquisition a step further. It requires the learners to decipher the new information and to apply it to different contexts. This leads to a greater sense of meaningful learning, whereas students collaborate in the construction of knowledge to solve a problem and make sense of future experiences. 12 participants revealed that they were able to apply the received knowledge in their teaching.

"We know our problems to implement flipped classroom."

"I really learnt a lot from this course. can be gradually applied to my class."

"I really love the fact that by watching the videos and joining in the forum, we were experiencing flipping class module that was being applied before we really attend the in-class course. In this way, we can at least be prepared on the concept of flipping class module and how it can be implemented."

Learning Platform. The e-learning environment has a significant role as learners only have meaningful educational experiences with well-designed courses and learning materials. Prior to that, it is crucial to pair suitable technology with the right curriculum and learning objective (Kidd, 2009). Pan et al. (2005) suggested that learning institutions to selectively use available technological features in virtual management systems that best facilitated effective course activities and increased learning outcomes. Chiu, Chiu \& Chang (2007) discovered that functionality, ease of use, reliability, flexibility, data quality, portability and integration have a positive effect on learner's satisfaction.

27 participants written that the applied learning platform provided them an enjoyable experience during the one-month online course. Example of written reply to reflect the situation such as "It's user-friendly." and "...can be access anytime." There 
were also other participants (3) whom felt that the platform was not robust to their liking. When asked what should be improved, the participants wrote the following:

"Menu options that are more convenient and simple."

"Its quite hard to return to the next page after we done posted article in the forum. Should have specific button at every page to make it more lenient for everyone to return or turn to another page."

"Using the application in handphone."

It was believed the feedback was made based on prior and current experience the participants have on with other applications such as Facebook and Instagram, which both are also mobile applications.

Course Design. Effective online learning is subsequently a well-planned instructional course design effort which meet both the course objectives and pedagogical needs.

These following three statements represented the quantitative section of the survey.

The online course was easy to navigate. $-85 \%$

The course was well-organized. $-76 \%$

The online activities made studying the course interesting and engaging - 91\%

The percentage is the accumulative of the Likert scale 4 (agree) and 5 (strongly agree). As seen above, the participants' choice on the both scales reflect their satisfaction on the online learning experience according to the item-course design. This was translated and seen in their written feedback from the open-ended questions.

"The best features in this course were giving the step or guidelines to make the flipping method."

The above feedback revealed that the arrangement of the content played a significant role in the learners' virtual learning journey. A study by Moore \& Kearsley (1996) cited in Kuo et. al. (2013) mentioned that course design would affect learners' interaction with the content and their instructor.

Further feedback such as "The course is implemented in such a way that is comfortable, easy to follow." illustrated that prescribing a suitable content arrangement would enhance the learning process. This was evident in a similar study by Lee \& Rha (2009). Lee \& Rha (2009) revealed that a highly structured course design is preferred by online learners as well as specified guidelines for each given task or assignment. The following feedback "easy, fast and not wasting time to go to course" also suggested that setting up the right pattern for learning content could actually "speed-up" the learning process. This aspect was the third highest frequency (39) of mentioned extracted from the qualitative data.

Instructions. Instructions are an integral element of course design. One can say that without instructions, it will cripple the course design. In other words, instructions are paramount for an online course especially clear and specific instructions. Since there is no prior face-to-face assistance, the learners must switch their own torchlight and interpret the sign-boards to guide themselves in moving from one section to another section, and deciphering what to do in each section. A simple yet powerful way to improve the quality of online instruction is to consider how the online course appears to learners when they first encounter it and later try to navigate through it (Lehman \& Conceição 2010). For this online course, the instructions were set for each 
section, and each sub-section. For example, in section Welcome on Board, instruction was written for the sub-section Course Manual (Refer to Fig 3). The explained the what was a Course Manual and its' objective for the course. In this online course, the instructions would also include check-list and reminders. The check-list would provide steps what the learners needed to perform first for each Pitstop.

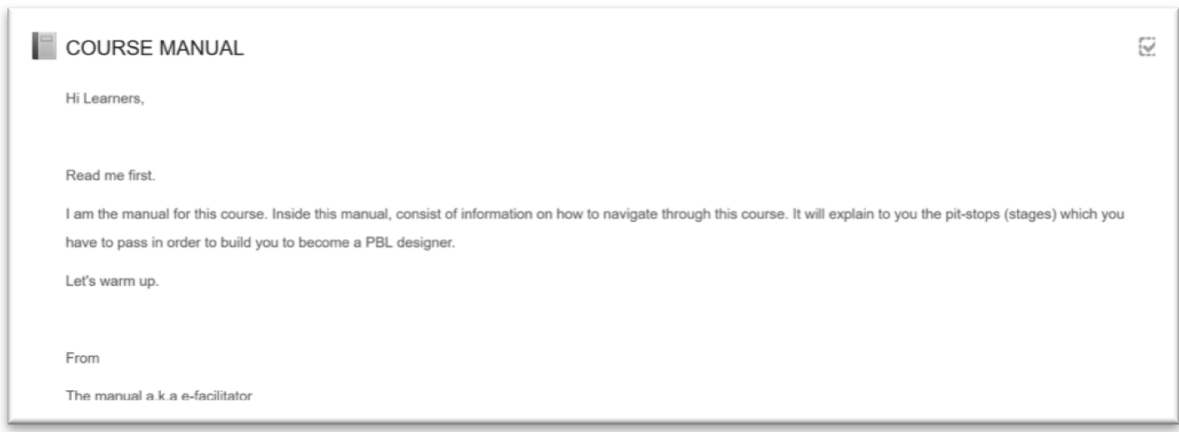

Fig. 3. Sample instruction

Before entering the Pit Stop, the learners were asked to read the Course Manual (Refer to Fig 4) which comprised of Welcome Message, Programme Description, Expectations on the learners, and Description of the Pit Stops. The Course Manual was created via the LMS embedded function book. A study also by Lehman \& Conceição (2010) have shown that a course orientation consisting of a welcome letter could create a safe and comfortable environment for interaction among learners.

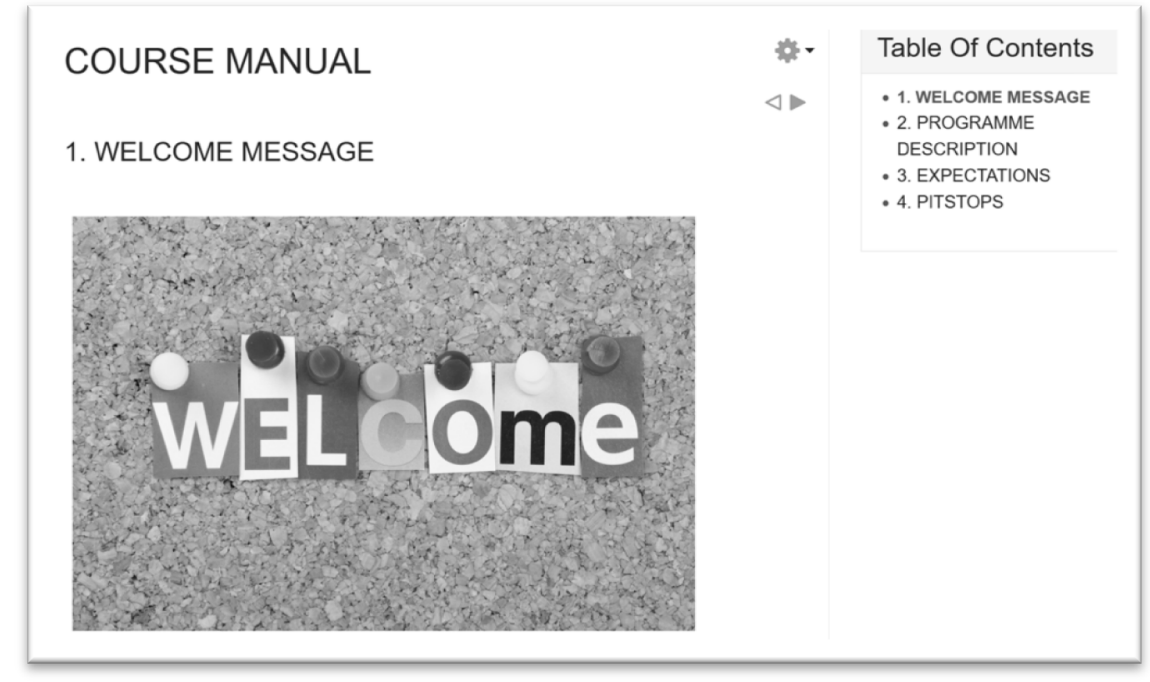

Fig. 4. Content of the Course Manual 
The learners welcome such efforts. Quantitatively, $85 \%$ of the learners agreed that the online course was easy to navigate due to the clear instructions. Study shows that a simple and clearly labeled course menu can facilitate better interaction (Harris et al. 2016) and Among the qualitative comments received from 13 participants were "easy to understand the instruction", "clear and systematic guidance" and "... easier for us to do each of activities because of clear instruction."

Social Presence. Social presence refers to the students' need to feel in communication with their classmates and recognise them as real people who share common interests and needs, as well as some online tasks, such as discussion forums (Barberà et. al, 2016). Richardson \& Swan (2003) argued that this item is tied with learner's satisfaction and it could be interpreted that low social presence may trigger poor learning experiences. 16 learners shared similar needs for this element.

"The forums also act as tools to trigger questions and issues that may arise."

"I can share and absorb some knowledge from friends in this forum."

"Participants can share ideas and comments in forum."

"Sharing useful information with other teachers and will let the participant to explore more on their own."

Based on the above feedback on social presence, it showed that the learners were able to indulge in deep learning from the forum discussion. The learning activity for each Pit Stop was posted in the forum, one of the LMS feature. The learners had to reply to the learning activity via forum. At the same time, the forum allowed the learners to embed images and files. This situation would permit a variety of more information to be added for the learning task. Other learners could see their peers' posts and shared files. Thus, the learners were able to learn from one another.

Instructor Presence and Learning Support. There were studies which mentioned the significance of learning support from the instructor or facilitator. For example, Eom et al. (2006) identified a significant link between learners and the facilitator's presence in an online course. This study found that the time that instructors take to reply to queries has a significant influence on learners' satisfaction and learning. Shea et al. (2006) found that students were "significantly more likely to report higher levels of learning and community when they perceived higher teaching presence behaviors". It was interesting to note that this did not occur in the online course. 3 participants highlighted lack of instructor presence and learning support from the instructor.

The written feedback from the participants were the following; "Video conference with the tutor for more understanding", "two-way communication" and "conducting a webinar before the final showdown". Such situation could have occurred because of how the prior items: course design, learning content and instruction were correctly executed to provide a learning environment which promotes self-directed learning among the learners. One participant wrote "For me, the course has encouraged me to manage my own learning...the activities encouraged me to make a research for additional materials..." Despite that, one cannot dismiss the fact that instructor presence and learning support is also a crucial item in providing satisfaction to the online learners. 
These request from the 3 participants for personal touch indicate that physical contact with the teacher is something that cannot be totally cut out from a learning experience. A study by Ross et al. (2014) argued that students were concern about the presences of their instructors from the beginning of an online course. In the same study, Ross et al. (2014) also commented that students were waiting for an embodied, authoritative and recognisable "teacherly moment" which cannot be achieved via embedded materials and activities. In other words, this could signify that the virtual presence of teachers in an online course advocates students' engagement.

\section{$4 \quad$ Limitations}

Several aspects of this study could have affected the research in such a way that the data findings do not represent the overall picture on adult learning in an online course. First limitation is the scale of the study. This research is confined to one online course. In order to obtain substantial findings, the research process should be done on more than one online courses. Not only that, the focus is on a group of academicians. However, online courses contain various fields with different student groups. Consequently, findings cannot be generalized to all online courses without a needs analysis done in their own setting. The next limitation was that the research process for the study was done as a one time. The research process could be done more with interview on selected participants.

\section{Conclusion}

The analysed data from the study shed answers to adult learners' satisfaction in online learning environment. An instructor needs to take note to include the following predictors when designing and managing an online course, either blended or fully online; (1) Learning content, (2) Knowledge acquisition, (3) Instruction, (4) Learning platform, (5) Course design, (6) Ability to transfer, (7) Instructor presence and social support

With the seven items balanced and checked, the facilitator or the instructor can be assured to receive similar written feedback to the one below.

"The work was challenging, the lectures stimulating, and there was a great sense of achievement at the conclusion of the course."

Future studies should look into how instructors monitor learners learning process such as providing instructors' feedback and administrating peer-to-peer interaction to learning activities especially for large number of students.

\section{References}

[1] Alexander, M. W., Perrault, H., Zhao, J. J. \& Waldman, L. (2009). Comparing AACSB faculty and student online learning experiences: Changes between 2000 and 2006. Journal of Educators Online, 6 (1) https://doi.org/10.9743/JEO.2009.1.2 
[2] Allen, I. E., \& Seaman, J. (2015). Grade level: Tracking online education in the United States. Newburyport, MA: Online Learning Consortium.

[3] Artino, A. R. (2007). Online military training: Using a social cognitive view of moti-vation and self-regulation to understand students' satisfaction, perceived learning, and choice. Quarterly Review of Distance Education, 8(3), 191-202.

[4] Bishop, W. (2002). Wendy Bishop on teaching with technology. Interview by Sonja Bagby. Kairos: Rhetoric, Technology, Pedagogy, 7(3). Retrieved from http://english.ttu.edu/kairos/7.3.htm

[5] Bourdeaux, R \& Schoenack, L (2016) Adult Student Expectations and Experiences in an Online Learning Environment, The Journal of Continuing Higher Education, 64:3, 152$161 \mathrm{https://doi.org/10.1080/07377363.2016.1229072}$

[6] Brindley, J.E., Walti, C. and Blaschke, L.M. (2009) "Creating effective collaborative learning groups in an online environment", The International Review of Research in Open and Distributed Learning, Vol 10, No. 3, 1-6, Retrieved from http://www.irrodl.org/ index.php/irrodl/article/view/675/1271 https://doi.org/10.19173/irrodl.v10i3.675

[7] Cercone, K. (2008). Characteristics of adult learners with implications for online learning design, AACE Journal, 16(2), 137-159.

[8] Choy, S. (2002). Nontraditional undergraduates (NCES 2002-012). U.S. Department of Education, National Center for Education Statistics. Washington, DC: Government Printing Office.

[9] Chiu, C.-M., Chiu, C.-S., \& Chang, H.-C. (2007). Examining the integrated influence of fairness and quality on learners' satisfaction and Web-based learning continuance intention. Information Systems Journal, 17, 271-287. https://doi.org/10.1111/j.13652575.2007.00238.x

[10] Conaway, W., \& Zorn-Arnold, B. (2016). The Keys to Online Learning for Adults. Distance Learning Issue: Volume 13\# $1,1$.

[11] Cranton, P. (1996) "Types of Group Learning." In Learning in Groups: Exploring Fundamental Principles, New Uses, and Emerging Opportunities. New Directions for Adult and Continuing Education no. 71, edited by S. Imel, 25-32. San Francisco: Jossey-Bass, 1996.

[12] Eom, S. B., Wen, H. J., \& Ashill, N. (2006). The determinants of students' perceived learning outcomes and satisfaction in university online education: An empirical in-vestigation. Decision Sciences Journal of Innovative Education, 4, 215-235. https://doi.org/10.1111/ j.1540-4609.2006.00114.x

[13] Forbus, P., Newbold, J. J., \& Mehta, S. S. (2011). A study of non-traditional and traditional students in terms of their time management behaviors, stress factors, and coping strategies. Academy of Educational Leadership, 15, 109-125.

[14] Gibson, D., Ostashewski, N., Flintoff, K., Grant, S., \& Knight, E. (2015). Digital badg-es in education. Education and Information Technologies, 20(2), 403-410. https://doi.org/10.1007/s10639-013-9291-7

[15] Gómez-Rey, P., Barberà, E., \& Fernández-Navarro, F. (2016). A cross-national study of teacher's perceptions of online learning success. Open Learning: The Journal of Open, Distance and e-Learning, 31(1), 25-41. https://doi.org/10.1080/02680513.2016.1151350

[16] Haley, G. R., \& Booker, J. E. (2012). Empowering non-traditional students to succeed in online programs. Journal of Human Resource and Adult Learning, 8(1), 71-79.

[17] Harris, H. S., Weber D., and Borgman J. 2016. "When the Distance is not Distant: Using Minimalist Design to Maximize Interaction in Online Writing Courses and Im-prove Faculty Professional Development." In Applied Pedagogies: Strategies for Online Writing Instruction, edited by Daniel Ruefman and Abigail G. Scheg, 17-36. Boulder, Colo.: Utah State University Press. https://doi.org/10.7330/9781607324850.c002 
[18] Kaminski, K., Switzer, J., \& Gloeckner, G. (2009). Workforce readiness: A study of university students' fluency with information technology. Computers \& Education, 53(2), 228-233. https://doi.org/10.1016/j.compedu.2009.01.017

[19] Kidd, T. T. (2009). Online education and adult learning: New frontiers for teaching practices. Hershey, PA: IGI Global.

[20] Kuo, Y. C., Walker, A. E., Belland, B. R., \& Schroder, K. E. (2013). A predictive study of student satisfaction in online education programs. The International Review of Re-search in Open and Distributed Learning, 14(1), 16-39. https://doi.org/10.19173/irrodl.v14i1.1338

[21] Lee, H. J., \& Rha, I. (2009). Influence of structure and interaction on student achieve-ment and satisfaction in web-based distance learning. Educational Technology \& So-ciety, 12(4), 372-382.

[22] Lehman, R. M., \& Conceição S. O. (2010). Creating a Sense of Presence in Online Teaching: How to "Be There" for Distance Learners. San Francisco, California: Jossey-Bass.

[23] Mayer, R. E. (2002). Multimedia learning. In Psychology of learning and motivation (Vol. 41, pp. 85-139). Academic Press. https://doi.org/10.1016/S0079-7421(02)80005-6

[24] Merriam, S., \& Caffarella, R. (1991). Learning in adulthood. San Francisco: Jossey-Bass.

[25] Merriam, S. B., Caffarella, R. S., \& Baumgartner, L. M. (2007). Learning in adulthood: A comprehensive guide. San Francisco, CA: Jossey-Bass

[26] Moore, M. G., \& Kearsley, G. (1996). Distance education: A systems view. New York, NY: Wadsworth.

[27] Nagel, D. (2009). Most college students to take classes online by 2014. Campus Technology. Retrieved from http://campustechnology.com/articles/2009/10/28/most-collegestudents-to-take-classes-onlineby-2014.aspx

[28] Newbold, J. J., Mehta, S. S., \& Forbus, P. R. (2010). A comparative study between nontraditional students in terms of their demographics, attitudes, behavior and educa-tional performance. International Journal of Education Research, 5(1), 1-24.

[29] Osgood-Treston, B. (2001). Program completion barriers faced by adult learners in higher education. Academic Exchange Quarterly, 5(2), 120.

[30] Pan, C.-C., Sivo, S., Gunter, D., \& Cornell, R. (2005). Students' perceived ease of use of an elearning management system: An exogenous or endogenous variable? Journal of Educational Computing Research, 33(3), 285-307. https://doi.org/10.2190/7M4G-R742W9FT-JX1J

[31] Park, J., \& Choi, H. J. (2009). Factors influencing adult learners' decision to drop out or persist in online learning. Journal of Educational Technology \& Society, 12(4), 207-217.

[32] Parsad, B., \& Lewis, L. (2008). Distance education at degree-granting postsecondary institutions: 2006-07. Retrieved from http://nces.ed.gov/pubs2009/2009044.pdf

[33] Pilar Gómez-Rey, Elena Barbera \& Francisco Fernández-Navarro (2016) Measuring teachers and learners' perceptions of the quality of their online learning experience, Distance Education, 37:2, 146-163 https://doi.org/10.1080/01587919.2016.1184396

[34] Politis, J. \& Politis, D. (2016). The relationship between an Online Synchronous Learning Environment and Knowledge Acquisition Skills and Traits: The Blackboard Collaborate Experience" The Electronic Journal of e-Learning, Volume 14 Issue 3, (pp 196-222)

[35] Puzziferro, M. (2008). Online technologies self-efficacy and self-regulated learning as predictors of final grade and satisfaction in college-level online courses. American Journal of Distance Education, 22(2), 72-89. https://doi.org/10.1080/08923640802039024

[36] Richardson, J. C., \& Swan, K. (2003). Examining social presence in online courses in relation to students' perceived learning and satisfaction. Journal of Asynchronous Learning Networks, JALN, 7, 68-88. 
[37] Ross, J., Sinclair, C., Knox, J., Bayne, N. \& Macleod, H. (2014), "Teacher experiences and academic identity: the missing components of MOOC pedagogy", Journal of Online Learning and Teaching, Vol. 10 No. 1, p. 57

[38] Shea, P., Vickers, J., \& Hayes, S. (2010). Online instructional effort measured through the lens of teaching presence in the Community of Inquiry Framework: A re-examination of measures and approach. International Review of Research in Open and Distance Learning, 11(3), 127-154. https://doi.org/10.19173/irrodl.v11i3.915

[39] Sugar, W., Martindale, T., \& Crawley, F. E. (2007). One professor's face-to-face teach-ing strategies while becoming an online instructor. The Quarterly Review of Distance Education, 8(4), 365-385.

[40] Tainsh, R. (2016). Thoughtfully designed online courses as effective adult learning tools. Journal of Adult Education, 45(1), 7-10

[41] Tweedell, C.B. (2000). A theory of adult learning and implications for practice. Paper presented at the meeting of the Midwest Educational Research Association Annual Meeting. Chicago, IL.

[42] Xie, K., \& Ke, F. (2011). The role of students' motivation in peer-moderated asynchronous online discussions. British Journal of Educational Technology, 42(6), 916-930. https://doi.org/10.1111/j.1467-8535.2010.01140.x

[43] Yang, Y. F., \& Tsai, C. C. (2017). Exploring in-service preschool teachers' conceptions of and approaches to online education. Australasian Journal of Educational Technol-ogy, 33(1). https://doi.org/10.14742/ajet.2635

[44] Yukselturk, E., \& Yildirim, Z. (2008). Investigation of interaction, online support, course structure and flexibility as the contributing factors to students' satisfaction in an online certificate program. Educational Technology \& Society, 11(4), 51-65.

\section{$7 \quad$ Authors}

Huey Zher Ng is with INCEIF, Malaysia.

Sakina Sofia Baharom is with MARA Corporation, Malaysia.

Article submitted 06 October 2018. Resubmitted 28 October 2018. Final acceptance 05 November 2018. Final version published as submitted by the authors. 